\title{
Two (Different) Types of Human Rights Duty
}

\author{
SALADIN MECKLED-GARCIA \\ University College London
}

\begin{abstract}
In this paper I introduce a (new) distinction in human rights theory, between two types of genuine obligations corresponding to human rights: a) obligations that require us to rule out specific considerations for treating people in a certain way, such as the obligation not to consider Jane's skin color when deciding whether she should be permitted to enter a shop or the obligation not to take political expediency as a consideration relevant to whether political opponents should be silenced, and b) an obligation to give some weight to different interests: those interests people have in enjoying certain conditions and those of people who must carry burdens to create these conditions, when deciding what must be done for rights holders. For example, we must weigh the interest Jane has in seeing certain improved access to secured health care versus the interests of other members of Jane's society in not facing significantly-increasing tax burdens, or seeing reduced social opportunities for their ends, as these will impact on their abilities to pursue their own personal life projects. Both types of interest matter, so to resolve how much health provision Jane is entitled to have we need to know how to weigh them against each other we need an index. These different types of obligations, with their basis in different forms of reasoning, cut across categories of human rights and can both exist for any one human right. Accepting the distinction means accepting that we must pay careful attention to how a human right is given content in the form of obligations. It also re-introduces conceptions of distributive justice as a necessary component in solving how conflicting interests should be weighed an "index" for such weighing.
\end{abstract}

Keywords: human rights; responsibilities; obligations; conflicting interests; weighing; categorical reasons; excluded reasons; distributive justice; fairness. 


\section{INTRODUCTION}

A slogan adopted by the United Nations, echoing an account by Henry Shue, says that the duties corresponding to human rights are to "respect, protect, and fulfil" those rights (Shue 1996: 52; CESCR 1999a: s. 15; CESCR 1999b: s. 46; CESCR 2000: s. 33). This, of course, means the duties are to respect, protect, and fulfil people's secure enjoyment of the content or objects of those rights as described in international instruments. However, a problem with these headings is that they do not explain how we should allocate the burdens of these different types of duties and justify the allocation for those that will execute them or bear the costs of their execution - ultimately the citizens of each society.

In this paper, I introduce a different categorization of duties. This cuts across, rather than underpinning, traditional distinctions between types of human rights - such as Civil and Political (CivPol) rights versus Economic and Social (EcoSoc) rights, liberty rights versus benefit rights, or even rights with positive obligations versus those with negative obligations, distinctions that have been debated in the literature. ${ }^{1}$ This new categorization is not intended to map onto debates where authors defend or dispute that such distinctions exist or use a categorization to undermine the importance of any specific group of rights. Instead, the argument lies within the sphere of genuine obligations. It neither challenges the existence of the two categories of obligations I set out, nor questions the rights to which they give substance. Indeed, for many traditionally understood rights in either of the above CivPol or EcoSoc categories, both of my types of duty will apply. The point of the distinction I introduce is rather to help us think about what it means to satisfy obligations and when it is appropriate to satisfy an obligation in one way rather than the other. The distinction focuses practically on how to adjudicate or claim different elements of a right, given the different obligations it can imply. As will become clear, when I set out the two different types of duty, adjudicating what it means to act on these two types of duties or to breach them amounts to very different things, implying very different tests.

The distinction I have in mind is between a) obligations that require us to rule out specific considerations for treating people in a certain way, such

1 The Civil \& Politial v Economic \& Social distinction is a de facto description of rights appearing in different instruments of the UN Bill of Rights (ICCPR v ICESCR); liberty $\mathrm{v}$ goods and benefits rights is a terminology introduced by Onora O'Neill (1996:131 ff.); Negative v Positive rights are discussed in (Bedau 1979); and positive v negative duties later by Shue (1996: $35 \mathrm{ff}$.); other attempts to distinguish human rights that are thought genuine from those that are not include the justiciable versus non-justiciable distinction, Justice Sachs (2000); see also Christiansen (2007). 
as the obligation not to consider Jane's skin color when deciding whether she should be permitted to enter a shop or the obligation not to take political expediency as a relevant consideration to whether political opponents should be silenced; and b) an obligation to give some weight to different interests people have in enjoying certain conditions and those interests of the individuals who must carry burdens to create such conditions. For example, we must weigh the interest Jane has in seeing certain improved access to health care secured versus the interests of other members of Jane's society in not facing significantly-increasing tax burdens, as these will impact on their abilities to pursue their own personal life projects. ${ }^{2}$ Both types of interest matter, so to resolve how much health provision Jane is entitled to have we need to know how to weigh them against each other - that is, we need an index.

Consider an example. In 2015, the government of Greece was criticized review of the Committee for Economic Social and Cultural Rights (CESCR) of the UN for failings in its EcoSoc rights provisions, such as basic health provisions (CESCR 2015: e.g., paras. 19 \& 20). Specifically, provision of health resources and access to them had been curtailed by government policy during an economic emergency, principally reflected in a sovereign debt crisis. The Greek government responded that it did not have the resources to keep those EcoSoc provisions at the prior level given the conflicting priority of floating the economy. Critics of Greece point out that it had options as to where to find resources to address the crisis: health provision was not the only one. It could have increased taxation of the affluent instead as a concrete response that is more specific than the CESCR's chide that the government could "do more". However, a question arises as to what the right way to understand the duty to fulfil the right might be, in terms of how burdens can be allocated to resource that provision without being unreasonable (imposing unacceptable levels of burden). Answering that question, I will argue, requires us to adopt the second model of obligations (b) above in that it calls for an index in weighing different and conflicting interests none of which are disqualified as irrelevant considerations to what we should do. That is a different question from the categorical one of whether the Greek government was appealing to unacceptable, irrelevant considerations, in distributing burdens the way it did.

In part 2 below, I set out this distinction in types of duties more clearly.

2 Throughout this paper I refer to "duties" and "justified burdens" as comprising the costs that people may have to shoulder to secure the satisfaction of certain interests for others. Duties are just one type of burden, whereas lost opportunities (opportunity costs) involving no obligatory action are another, thus the need to specify both elements. I also use duty and obligation interchangeably. 
In 3, I focus on the second obligations model, underpinned as it is by reasons relating to how one should weigh competing but legitimate interests and which I call 'Weighing reasons'. In 4 I return to the other model of obligations, those based in what I call 'Decisive reasons'. In 5 I show why some key objections to this distinction between the two models and its application to human rights duties do not work.

\section{THE DISTINCTION}

Another way to frame the distinction among types of duties I have in mind is in terms of reasons and actions. ${ }^{3}$ On the one hand, we consider a specific action type in terms of the considerations for it and whether there are reasons to rule out those considerations - and with them the action. This might also work with omissions where a specific action should not be omitted for certain considerations. ${ }^{4}$ The government omitting to distribute food aid because it does not want to develop an aid plan for the poor, viz. poor citizens will not generally bring electoral dividends, makes it wrongfully neglectful of those citizens. In such cases, we have reasons to rule out the consideration, the electoral calculations, supporting the omission and with it the omission itself. ${ }^{5}$ However, ruling out omissions requires ruling out the positive considerations entertained in favor of wrongfully omitting the action. On the other hand, we have reasons to give a certain weight to some considerations when determining what action should be carried out, given the different competing considerations. The proposal to increase contributions towards educational provision must be considered by weighing the benefits the provision brings to those who can access it against what it requires in burdens for those who must, say, be taxed to finance it. We do not have a categorical reason to provide a given amount of education for any person, in this case, until we have found a

3 For one theorist, a practical reason is something "that counts in favour of some attitude or action" (Scanlon 2004: 231). For clarity in the text when referring to "reasons" I shall exclusively be referring to obligation-generating moral considerations, and by "considerations" I shall mean any candidate reasons (in Scanlon's sense), moral or nonmoral, for acting or omitting to act.

4 I make no fundamental distinction between actions and omissions (the failure to perform a given action) in this paper. One can have an obligation to perform specific actions as well as an obligation not to perform certain specific actions (to omit).

5 The idea that there are special moral reasons that indicate considerations we can disqualify or exclude as reasons in moral deliberation is present in a number of authors (Dworkin 1984; Waldron 2000: 302 ff.; Dworkin 2010: 330). Scanlon identifies a special brand of 'complex reasons': those reasons we have to not take certain other considerations into account. These can include reasons not to weigh or promote a given aim (Scanlon 1998: 50 ff.). The general idea that moral reasons can 'silence' other considerations is present in John McDowell (1998, originally published in 1978: see 92). 
justified way to weigh the different interests against each other and arrived at the amount that is mandated by this weighing.

We can call the first kind of reasons "Decisive":

Decisive: No considerations within a range, $R$, such as considerations a, $\mathrm{b}$, or c, etc., is admitted as a (pro tanto) reason in deciding how to treat someone. Actions based on those considerations are ruled out.

Considerations can here include people's interests, which can be disqualified as having no weight in our deliberations. For example, consider a state claiming an interest for itself or its citizens in allowing slavery to take place. That interest should be given no weight because it demeans and diminishes human beings, treating them as objects of ownership. Weighing the interests of one group (the slavers) versus another (the potential victims) is itself decisively ruled out because of what the pro-slavery interest implies about other human beings. ${ }^{6}$

Where we have reason to weigh interests against each other, we can call this "Weighing":

Weighing: For a range of beneficial outcomes $\mathrm{O}$ that persons might enjoy, such as p, q, r, etc., the securing of which depends on others persons limiting their enjoyment of a range of outcomes, $\mathrm{S}$, such as $\mathrm{t}, \mathrm{u}$, v, etc., we must assign a certain weight to these outcomes such that we know how much curtailment of S-type outcomes it is justified to assign to those that will experience the curtailment, given the O-type outcomes this will produce.

Simply, "Weighing" assigns obligations according to some idea of appropriate weighing and balancing between certain benefits for persons and those burdens required to produce/secure the benefits. I will come to what such weighing amounts to and how it might be done below. For now, consider that the fact that we can increase street lighting by $50 \%$, and with it personal security by $5 \%$, does not by itself tell us whether we should do so. First, we must look at the costs, in terms of lost opportunities or outcomes to others. A proposal to reduce road traffic speed limits down to $20 \mathrm{mph}$ on all roads, even if it improves safety outcomes gained, has to be weighed against the losses it would bring in many other areas of life; and that weighing, done right, might indicate that a global $20 \mathrm{mph}$ speed limit

6 By "interest" here I mean an element of people's wellbeing, in the sense of what does or can make their lives go better if satisfied. Some theorists claim that one cannot have an interest in unjust things, and that is why some "interests" do not count for the purpose of grounding rights (Tasioulas 2015: 49). However, if we are justifying human rights this would be circular, appealing to a right (justice) to explain a right. Not only that, there is an important sense in which interests relate to a person's life plans, even mistaken life plans, rather than what is good per se. 
constitutes too much of a loss in ways that matter for people's lives, even if it would avoid a certain amount of death-risk on the roads. The weighing must be done to determine what we should do. We would not, however, accept similar reasoning when considering killing of one's unhelpful boss, say, such that we weigh the benefits to us against her personal losses, assign weights to each on some scale, and then calculate what to do. Rather, entertaining that very calculation smacks of psychopathy - we have a compelling reason not to treat such considerations as operative reasons at all, because treating people as part of such a calculation is excluded by their status as persons. Secondly, where weighing is appropriate we need to introduce a way to weigh the securing of this range of people's interests given the costs of doing so to others. That might be done by introducing a certain index to do this weighing, such as that for every gain $\mathrm{X}$, a certain amount or type of cost $Y$ is acceptable for others, but no more. I will shortly come to how to weigh.

Weighing reasons allow both that the amount of provision towards satisfying a given interest for each person is determined according to the fair burdens that can be imposed on others in providing it. It might also allow that the numbers of persons having access to that provision are also limited, according to the fairness of the required burdens, as where people in the worst conditions are prioritized given what can fairly be imposed in the form of taxes at a certain juncture. Fairness is a value that itself needs setting out, and there are different accounts. Some see fairness as equivalent to reciprocity, others to focusing on the least well-off. ${ }^{7}$ For now, I am using it to indicate what burdens people may be expected to accept given the benefits, where no reason exists to cancel out the burdens as a valid consideration in deciding the correct course of action. The question of how we should weigh costs against benefits works along both axes (individual provision/numbers of individuals provided for). I will leave open the question as to along which axis balancing is permitted, in the sense set out above. If one accepts a basic equality restriction that no person can receive less provision than any other - which would require a special justification - then only one kind of balancing will be permitted. I am also leaving aside the question of weighing or deciding what to do when rights themselves (as opposed to the interests underpinning rights claims) clash. For my case that two types of reasons exist it is enough that

7 Whilst Rawlsian fairness may have started out as Hartian reciprocity, it is not clear that Rawls' theory of distributive justice, and especially his "difference principle", is a reciprocal version of fairness. The original position models fairness in terms of what people would reasonably accept as a potential outcome for them: “...the idea of fair terms of cooperation: these are terms each participant may reasonably accept, and sometimes should accept, provided that everyone else likewise accepts them." (Rawls 2001: 6). 
sometimes we must weigh competing interests and sometimes competing interests are silenced.

Decisive reasons are pro tanto moral reasons or obligations. That is, there may be circumstances where one is forced by other moral reasons or obligations to go against these reasons. That would not, however, be a case where the reasons were extinguished. So, suppose a police officer was forced to act in a racially discriminatory way in order to prevent a murder (thus mollifying the murderer until backup arrived): that would not render the reasons to not racially discriminate invalid in such a case. There are other overriding reasons all-things-considered take priority in these circumstances. This is important because the mere existence of potentially overriding reasons all-things-considered, as in the above example, does not turn all Decisive reasons into Weighing reasons. That would be the case if Weighing reasons were only, or principally, triggered where we had to adjudicate between pro tanto obligations. But Weighing reasons exist where no pro tanto moral obligations exist, mandating us to act, but where valid considerations are nevertheless weighed and balanced. No obligation survives this balancing or weighing, all-things-considered, and we wrong no one by fairly adjudicating between the competing interests. Thus, consider the benefits of university education and the cost of taxes to provide it. If we decide on a certain amount of taxation, and resulting university provision is acceptable, we are not thereby deciding to breach a pre-existing pro tanto moral reason not to tax. The question of whether we should tax or not is always posed in relation to the benefits that might be derived from taxation. The interests people may have against taxing at this level may be outweighed by the interests in university provision. In which case, we would have a resulting reason to tax, which is a pro tanto reason, not a group of separate pro tanto reasons.

The focus on disqualifying considerations in Decisive reasoning may be thought to imply that reasoning is wholly about intentions, versus the objective features of the actions themselves; indeed that has been raised as an objection to one version of this approach (Möler 2009: $762 \mathrm{ff}$.). The objection poses a dilemma: either we focus on subjective states in pursuing an action or we focus on objective reasons of the action. Focusing on subjective states is problematic because we may be unable to determine them, and part of what one can acceptably intend will anyway depend on what an action objectively does - intentions deriving their moral acceptability form the actions they intend. Focusing on objective effects, however, will focus on how interests are affected and that goes beyond the specific reasons the agent may have for carrying out the action. For my purposes, here we can refuse the dilemma. The objection runs together 
"intention behind" with "reasons for". We can consider what can best explain the action in its context in terms of the considerations that might support it, the reasons for it, and decide from those if any could plausibly render the action permissible because they are not disqualified considerations but genuine reasons. Indeed, some types of action are already differentiated by their inherent incorporation of a certain kind of purpose that can never be an acceptable consideration for acting. The action of enslaving a person inherently incorporates extreme purposes with regard to human instrumentalization such that they cannot be divorced from a proper interpretation of the action. Below I will identify the kind of moral basis one might cite to exclude reasons of this kind; but for now, we can see that it is not the subjective intention, but the publicly defensible interpretation of an action and its plausible supporting reasons that matters for Decisive reasons.

Now, it might be objected here that there are moral theories that not only permit weighing, but endorse it, in all cases, meaning the cases I have described as Decisive are only ever provisionally decisive. Some forms of consequentialism, such as those incorporating an unconstrained wellbeing-maximizing instruction, might indeed assign weights to the option of murdering my boss, as well as reducing speed limits on the road. They arrive at both conclusions about what can or should be done by weighing. A significant attraction in rights thinking, however, which is also present in the aspirations for human rights standards, is to limit that kind of reasoning. Rights are seen variously as limits, side constraints, or as invoking interests that are "qualitatively" different from other interests that can be simply weighed against each other. ${ }^{8}$ How, or why, such qualitative limits exist depends on one's theory of individual-centered imperatives, but one thing any such theory would need to do is explain certain considerations as peremptory, such that certain considerations, including those relating to satisfying other people's interests, cannot count against them even in very large numbers. To do that, those other considerations must have a weighting of zero in confrontations with these interests. Examples of such, pro tanto, weightless considerations would be justifying the political exclusion of others on the basis of race or the sacrifice a person's life on the grounds that it brings satisfaction in terms of (whatever number of) other people's life projects. To be able to do this, we need a reason to set the relevant considerations to zero in these confrontations, and that kind of reason needs explaining beyond an appeal to an unexplained terminology of qualitative differences between 
interests. ${ }^{9}$ If one accepts that there are such rights, then one needs that reason-based explanation.

Now, if this is right, it means that, whilst Decisive reasons focus on what counts as an acceptable consideration for an action (or omission), Weighing reasons are index-focused. They concern what should be weighed against what and on what basis, as an index for negotiating between different and valid competing interests, in order to arrive at normative conclusions about what can or should happen.

Decisive reasons are more straightforward. Key human rights or basic rights include rights not to be arbitrarily detained, arbitrarily killed, tortured, or enslaved, for example. ${ }^{10}$ It is important to note that what is ruled out by such rights relates to certain types of treatment, distinguishable not simply by the interests that they affect, but also by the basis for the treatment. We must not simply look at the impact on certain interests of being detained to determine whether it is morally acceptable, but must also consider whether it is arbitrary: meaning there is no compelling reason for it. If the non-arbitrariness test is passed, then detention can be permissible. It is also possible that negative impacts on interests such as one's interest in being free from coercive force, from having one's bodily integrity attacked, or from having one's life threatened are not by themselves the basis for ruling out certain actions. Killing in self-defense, forcibly coercing a detainee to prevent them carrying out a crime or from escaping justice, would both seem to be compatible with human rights standards. Killing for personal advantage, coercing someone with the aim of convenience, interfering with bodily integrity for material advantage or for no good reason, are all ruled out. With some human rights, the disqualified purpose is already built-into the description of the right. So, torture incorporates the purpose of using attacks on a person's wellbeing (infliction of grave pain) to either break their resolve in order to extract something from them against their prior conviction, such as information, punish them, or enjoy their suffering. Slavery incorporates the notion of ownership or control such that one person's exercise of her will in directing her life and person is subordinated to the aims of another. The attack on the interests in question, on being free from pain or being free from restraint or free to do as one wishes, is not by itself obviously prohibited. One might legitimately apply very serious pain to prevent an attacker harming another person, and that would not constitute a violation of a

9 Waldron, for example, never explains the notion of 'qualitatively' different interests that he takes to underpin rights (op cit).

10 These are clear core candidates for moral human rights, also reflected in international instruments (viz. ICCPR 1966/1978: Arts. 9, 6, 7, 8). 
human right, even pro tanto. This indicates that it is the way that interests are attacked - on the basis of what consideration or purpose that this is done - that determines the acceptability of the actions.

Here, one could object that the interest in question is the interest in being free from slavery, for example, such that it is an attack on these and not the considerations behind the attack that matters. That way, the effect on interests, and not the reasons behind the action affecting them is what matters in explaining human rights obligations. But not only is this an ad hoc move, introducing sui generis interests identified by type of treatment; this response still needs to explain why some interests are special, in the sense of being capable of disqualifying other considerations and not merely outweighing them. The slave owner's interest in holding slaves should have a weight of zero in deliberating on what to do if many slave owners are not to skew the figures on whether slavery is acceptable. In which case, we need a reason to disqualify them and the interest taken on its own will not explain that reason.

It is worth emphasizing here that Decisive reasons do not only exclude actions. Their focus is on disqualifying certain types of considerations as relevant to deciding how to act. They can also disqualify consideration that apply to omissions - as when a government neglects the safety of its citizens. Decisive reasons cut across negative-positive rights or even negative-positive duties distinctions because they are reasons to disqualify considerations; and they rule out actions or omissions in so far as they are supported bydisqualified considerations. These can include considerations that fail to sufficiently take into account the effect of a policy on citizens, and thereby imply neglect of their interests. Decisive reasons do not only apply to CivPol rights as traditionally understood. They can apply to considerations in the way EcoSoc rights are distributed. A state that prevents Jay from accessing a hospital because of her race or gender, where the hospital is not dedicated to group-specific ailments, will thereby breach a Decisive reason. Such considerations are disqualified when determining how to distribute social goods. What Decisive reasons cannot tell us is how to fairly determine the balance between interests, benefits and burdens when weighing these is appropriate, and consequently how much of a given social good is to be provided. That question concerns the correct index for weighing these interests against each other in determining what to do, implying a different kind of moral consideration.

Weighing reasons are more complex because considerations against providing certain outcomes for people can include interests that are not easily dismissed or disqualified as inherently invalid, yet do not themselves ground decisive reasons. So, for example, the human right to health or 
education are often taken as entitling people to fulfilment in the form of a certain amount of benefit provision in these categories of (health and education) interest (CESCR 1999b: s. 47; CESCR 2000: ss. 33, 36, 37, \& 44; Also Bilchitz 2007: 195). But it cannot be the case that a person has a claim against grounding an unconditional duty for others to provide $\mathrm{N}$ amount of health provision or $\mathrm{N}^{*}$ amount of educational provision, given that providing these requires those others to take on burdens to do so that would represent personal costs in pursuing life aims. Consider a level of resource requirement, $\mathrm{n}$, needed to achieve educational provision $\mathrm{N}$, that imposes on fellow citizens a duty to give up pursuing any personal life aims not dedicated to advancing $\mathrm{n}$, but instead to adopt life-shaping aims around achieving $\mathrm{n}$. They would have to decide their career choices and personal goals in terms of a personal commitment to what better achieves $\mathrm{n}$. Achieving $\mathrm{n}$ might require citizens to further restrict their personal lives, limiting their friendships in number so as to maximize resource and time towards contribution. Untrammeled, obligatory dedication to $n$ would reach deep into their lives as separate persons that would otherwise be guided by a sense of their own projects and pursuits. These requirements are unreasonable in the sense of undermining one of the points of a liberal and egalitarian morality: individuals living the lives according to their values and best lights. Unlimited instrumentalization should be an unreasonable demand, even for egalitarians. ${ }^{11}$ So, we need some clear sense of the limits of reasonableness. Whilst many authors mention reasonableness as a limit, or concede that no "excessive", "unreasonable", or "overly burdensome" requirements can be expected, these views always leave the criteria for reasonableness or excessiveness un-specified. Nor do they even supply a decision-procedure or principle that we might use to arrive at such an answer. ${ }^{12}$

In addition to reasonableness problems, there are also matters of fairness. Demanding large contributions from some citizens, even if these demands are consistent with allowing them to choose and pursue personal

11 In the words of G. A. Cohen, they would turn each person into an "engine for the welfare of other people" or "slaves to social justice". Cohen says that this requirement would be "excluded by a legitimate personal prerogative [that] grants each person the right to be something other" than this (Cohen 2008: 10).

12 Viz. whilst Cohen, supra, accepts a balance between other-regarding contributions and a personal prerogative (11), but gives no indication on how to determine the proper and just balance between the two (other than to claim we intuitively understand it [ $6 \mathrm{ff}$. and 354 ff.]). Other examples of accepting limits but giving no account include Buchanan (2004: 89, 92, 94 n.8), Stemplowska, who concedes duties to provide resources apply "if such resources can be provided at a reasonable cost to the provider"(Stemplowska 2009:468), and Gilabert, who also acknowledges there are limits to contribution but gives no account of those limits (Gilabert 2012: 47). 
aims, can still be unfair. That is because one can ask whether allowing the burdens to fall unevenly on some citizens treats those citizens with equal concern. Allowing some citizens more opportunities, or fewer burdens, to exercise their capacity to pursue their personal goals means treating them differently, and the differences have consequences for how they can pursue distinct lives. The need for fairness requires a positive account of how interests - both basic ones and those in pursuing distinct lives - can be balanced so that citizens are treated with equal concern, and thus fairly. An account of how to weigh interests fairly is, however, different from an account that disqualifies certain considerations for action.

Of course, there may be circumstances where fairness considerations are not pertinent. It might be argued that one ought to save a drowning child, even if one has saved many such children recently-just because one is confronted with the drowning child. Introducing fairness here is out of place. However, what precisely matters about the interests in play in the cases I have identified is that they are not rescue cases triggered by special circumstances of direct confrontation with the jeopardy of specific sufferers. Rescue cases are most plausible when considerations relating to a reasonable dispensation to prioritize one's own aims to guide one's life are absent, and so are considerations focused on the fair distribution of opportunities to pursue one's life aims. This is reflected in the number of authors working on rescue that look for characteristics to demarcate these cases in terms of the specificity of the circumstances - such as "being confronted" with another's plight, or being in the "proximity" of someone in peril. ${ }^{13}$ Certainly, any attempt to generalize from the mere fact that someone lacks basic interest satisfaction in a specific rescue case to a duty to contribute to basic interest satisfaction for all who need it, will introduce the need for a Weighing reasons model.

\section{ACCOUNTS OF WEIGHING REASONS}

If my above analysis is correct, then there are two types of duties, and two types of reasons that underpin them, corresponding to human rights standards. The point of this distinction is not to reject either type of duty but rather to invite reflection on what these duties demand, in the form of theories that give them content. The distinction is also not intended to rule out either duty model as relevant to human rights, in the way that perhaps debates on whether human rights are (technically) rights are intended to

13 What triggers rescue duties is a matter of dispute. A number of theorists propose proximity, (Miller 2010: 23 ff.; Kamm 2007: 379) while others focus on 'confrontation' with a specific person's case (Dworkin 2010: $277 \mathrm{ff}$.) as the defining feature. 
do (Cranston 1973; Bedau 1979). I deal with the question of whether this disjunctive analysis challenges the status of human rights as rights below. For now, if there are genuine Decisive and Weighing reasons, then they will generate obligations. Given the nature of the two types of claims, and any one human right will need both types of reasons and obligations to give it a well-articulated content.

By introducing the complexity of types of duty and the reasons that underpin them I also introduce some necessary complexity in our understanding how human rights can or should be claimed. Where the matter is simply one of Decisive reasoning, certain actions or omissions are categorically ruled out because of the character of the considerations that support them. Where Weighing reasons are appropriate, adjudication will need more information about what it would take to provide different levels of provision, and it will also need a principle for weighing the provision against the cost. This can only mean that an account of distributive justice is required.

For states seeking to comply in a principled way with their human rights obligations, determining a principled (reasonable and fair) way to carry out this balancing will be indispensable. That involves having a clear sense of what fairness can demand, in the form of a justifiable principle of fair distribution of benefits and burdens (a principle of distributive justice). Whilst there is little or no literature on fairness for human rights, the literature for principles of distributive justice is much richer and more advanced.

A rare exception to the lack of attention to, or even recognition of, this problem in human rights literature is David Bilchitz, who argues that we should accept a "core obligations" model prioritizing certain demands for fulfilment of interests, and progressive taxation as a means to resource the provisions (Bilchitz 2007: 88-89). Bilchitz's basic idea is that the more wealth people have, the more diminished are the returns on that wealth as utility for those that enjoy it (ibid). Thus, requiring contributions from those with more wealth is a less demanding (and a more marginal) burden than from those at other income levels. This, he argues, supports a progressive taxation solution to the supply question. But, whilst it is commendable that Bilchitz at least recognizes that there is a problem to be addressed, his response does not solve it.

While the response explains where to prioritize contributions, it either fails to explain what constitutes a fair contribution or it implies an implausible account of fairness. To take contributions at the margin - i.e., from the better-off first - does not indicate any limit on how much should be contributed. It is possible, on this instruction, to simply keep on taking. 
If there is no limit with an accompanying justification, then this not an account of fair contribution so much as an account of the order in which to collect contributions. One could come up with a limit, say of a certain level of wealth, but that would require justification as the right account of fair cost distribution. It would also imply that taking more was wrong, because unfair, and correspondingly right holders could only claim what was achievable with this level of contribution. Bilchitz does not supply an account of this kind of fairness. But we can consider some alternatives.

Perhaps, implicit in the progressive tax idea is the view that people must contribute up to that point where their own rights are threatened. That is, they are allowed to keep enough resources to be marginally above basic interest satisfaction. However, it is unclear why that is what constitutes a fair contribution. Bilchitz himself focuses on basic interests as setting a threshold of 'core obligations' for EcoSoc human rights. ${ }^{14}$ But that threshold seems too low to act as the bottom limit to which contributions can acceptably take a contributor, as a matter of fairness - it gives little or no weight to the value of respecting people developing and pursuing distinct life-shaping aims. It would imply that where some people were below the threshold because of a deficit in resources, potential contributors would always forfeit opportunities to personally work towards obtaining resources to advance their life-shaping projects and aims. This seems to rule out the prospect of pursuing a meaningful life through one's work and effort. It yokes the life of each individual, in the sense of developing and pursuing projects and goals that are one's own, to the sole aim of achieving a certain wellbeing level for others. Of course, the claim is not that people have unlimited rights to this pursuit, it is rather that it should have some fair weight.

It is important to parse out the issues here. There is a level of treatment for people that is prohibited, and would be covered by an account of Decisive reasons. That does not set a level of provision or contribution, except in so far as it rules out certain considerations (including some considerations about contribution or cost) as relevant to provision. When considering behavior such as the enslavement of others, cost considerations

14 Bilchitz defines minimum core in terms of interest fulfilment that secures near bare survival (Bilchitz2007:221). It is worth noting that Bilchitzdistinguishesimplementation duties, what he calls "unconditional rights", from the content of the rights themselves, which he calls "conditional rights" because their requirements being categorical depends on context and resources ( $77 \mathrm{ff}$. \& $220 \mathrm{ff}$.). The latter, somehow, symbolically go beyond what is required at any one time by unconditional rights. This distinction is troubling in my view, given that the normative content of a right is precisely a matter of what can justifiably be demanded from others, and a right considered distinctly from its normative content seems a mysterious idea. However, in this paper I am only concerned with the justification of types of duty. 
(of spurning slavery) to those doing the enslaving are irrelevant. However, when considering Weighing reasons, we must find a way to balance interests and determine fair limits for those contributing towards the fulfilment of human rights. The limits here are not the same as in Decisive reasons - they are not set as limits on the kind of considerations that can count, but by deciding how much of one set of acceptable interests it is fair to give up for another set-and so what can fairly be expected of contributors. However, the proposal that we should set the limits on contribution at the point at which "basic" or "core" interests are affected indicates that no one has a right to pursue a distinct life of their own so long as they can contribute more towards others reaching the satisfaction of those basic or core interests, however many people may be in that position. Here, reasonableness can still be preserved by not requiring people to prioritize the project of contributing to the raising of each and everyone's wellbeing levels, as one's life aim. That would be an illiberal consequence that made a person's conscience and life aims an instrument for the improvement of wellbeing. But even avoiding that, it challenges fairness to require each potential contributor to limit their pursuit of personal aims (save those that benefit overall interest fulfilment) to zero until all others have their basic interest satisfaction secured. It means no one is permitted to pursue resource opportunities, for their personal goals, that diverge from contributing to that goal, which is a challenging conception of fairness given that it does not give any weight to the interest in living a distinct life.

One could try to define the baseline differently, so that it captures those resources and opportunities needed to live a meaningful life, say. This might also solve associated problems, such as that in today's world the above measure of contribution might consign everyone to a life where they cannot pursue any aims that require resources above those necessary for basic interest satisfaction. People, on that approach, should give up any resource that places them above the core interest satisfactions, so long as richer people were the first to give up their resources. This is a worrying implication. I am assuming that the advantages above basic interest satisfaction that people have are not all or even mostly due to exploiting or oppressing those below the basic interest satisfaction level, so we are not considering those more straightforward cases of just rectification for wronging others. In which case, the yoking of individual life opportunities solely to the aim of increasing wellbeing for others implies they cannot legitimately pursue meaningful purposes of their own.

The only solution to this problem seems to be to allow that the limit on contribution is set so it allows enough resources to live a meaningful life. But that raises a set of serious problems too. Any attempt at settling an 
objective definition of a meaningful life that overrides subjective conceptions of what people find meaningful, will be illiberal in that it demands the state adopts a conception of a meaningful life for all, even those that reject the one proposed by the state. One could try to develop a conception at such a level of abstraction that it can encompass very many conceptions, say by focusing on a certain level of autonomy or reasonsensitivity in guiding one's life..$^{15}$ But such abstract conceptions are compatible with a wide variation in life projects and, consequently, a wide variation in the resources people should have the opportunity to pursue to put towards those goals. The idea of a compelling general conception of a meaningful life that inherently sticks to the resources needed to pursue it seems implausible. The alternative, of simply taking subjective understandings to define a meaningful life, is even less likely to establish a specific resource threshold to which they all subscribe.

Of course, in the sphere of debates about distributive justice theory, which is effectively where we find ourselves presently, there are views that seems to focus on a threshold as the basis for justice. Sufficientarianism suggests we can have a threshold of resource distribution where each person has "enough", and permits anyone above that level to have as much as they can obtain that is still compatible with everyone having at least as much as the threshold. ${ }^{16}$ Importantly, however, these views do not limit sufficiency either to a fixed point, or at the level of basic interest satisfaction. The idea is that people should have enough for a decent human life, and what that implies can vary and expand depending on one's social circumstances (See Casal 2007: $313 \mathrm{ff}$. \& $323 \mathrm{ff}$.). If sufficiency views simply asserted the threshold of sufficiency as basic interest satisfaction and mandated unconditional redistribution down to that, they would offer a categorical account of Weighing reasons. But that approach would suffer from the very problem to which we are trying to respond - the unfairness of yoking everyone's life aims and opportunities solely to the aim of increasing wellbeing up to certain level for everyone. Instead, space for pursuing a meaningful life is needed. Sufficientarian views also do not seem to offer a useful account of that (see Casal 2007: $313 \mathrm{ff}$.).

Note that in now considering fair arrangements, and accounts of distributive justice, I have departed from the simple rights view justifiable on the Decisive reasons model. For fair arrangements, we need a justified principle of distribution (within what Decisive reasons permit). That is: we are engaged in considering the fairness of different possible principles

16 E.g., Sufficientarianism in distributive justice (Frankfurt 1987; Crisp 2003) and as applied to human rights (Brock 2009: $62 \mathrm{ff}$.). 
according to which relevant agencies can arrange benefits and burdens, opportunities and obstacles. These are typically defined and pursued through the allocation of socially recognized rights and duties to citizens, by an agency that can legitimately make such allocations. Societal fairness here asks according to what principles should authoritative agents create cooperative arrangements between contributors and beneficiaries using allocations of rights and duties. ${ }^{17}$ Where Weighing reasons are appropriate, the principles do not mandate outcomes for beneficiaries at all possible costs, but instead offer principles for deciding what costs are acceptable in exchange for which benefits. The literature on such principles is rich and varied, and interestingly it has been significantly ignored by people proposing theories of human rights. Yet, as we now see, if Weighing reasons do characterize the content of well-known human rights duties, such as duties to fulfil, addressing the problem of how to weigh interests is unavoidable. I will consider some arguments for avoiding that model below. For now, I look at the implications of treating this as part of distributive societal justice theory.

A significant category of principles of distributive justice address the above problem of a fair opportunity to pursue a meaningful life, even whilst redistributing to assist those who have less opportunities. Some of these views allow certain freedoms and opportunities to pursue increased access to resources, but conditionally. People can pursue and achieve certain personal, resource-requiring goals on the condition that these opportunities and achievements are simultaneously of benefit to people with less opportunities to pursue resources for their own aims. These views differ from proposals that require contributions up to the point in which contributors' own basic interests will cease to be satisfied because the latter exclude people pursuing additional resources over and above the basic threshold. Conditional opportunity theories condition the opportunity to pursue such aims including by pursuing resources on their simultaneously contributing to the social good. So, opportunities to pursue extra resources towards advancing a musical or artistic project would only be permitted in so far as these pursuits also contribute to social benefits - in the form of redistribution of a component of their resources. For example, a Rawlsian maximin principle requires social institutions to permit people to pursue inequality-producing resource aims, but only

17 I am not here limiting distributive justice to these institutional considerations, but rather stating an important role that distributive justice must play, and indeed does in the accounts of theorists as varied as Rawls, Dworkin, and G. A. Cohen. For an extensive discussion of the distinctive role of the concept of distributive justice see (Meckled-Garcia 2016). 
where this helps the least advantaged in society. ${ }^{18}$ Similarly, Dworkin's account of justice as equal concern, and in turn of societal equal concern as equality of resources, allows people to pursue distinct life projects so long as society aims to guarantee equal starting resources for all to pursue their projects, and everyone who can, contributes to social insurance for those that might meet difficult resource circumstances (Dworkin, 2000: pp. 73 ff.).

Accepting that some human rights duties or justified Weighing reasons must apply, has the upshot that whilst the principles for weighing different interests will remain the same, their application will vary according to which interests are in play to be weighed against each other in any one context. Fairness demands different things where pursuit of a personal end will simultaneously contribute to the social good compared to where that pursuit has no social dividend. The principle is the same in both cases, but the interest distribution and relation differs. With Decisive reasons, one is not relating interests that might differ but rather determining what kind of considerations are acceptable or relevant to a course of action. Moral reasons should be able to rule out a range of these $a$ priori, and with them the actions they support. Distributive justice principles, because of their conformity to the Weighing reasons model, do not have this a priori consideration and action-focused component.

Of course, here I do not propose to support or advance any one theory of distributive justice. A whole range of candidate principles exist in the literature that try to answer the fairness problem, including utilitarian, egalitarian, prioritarian, and sufficientarian views. Some function by introducing more specific opportunity-focused, resources-focused, welfarefocused, access-to-welfare-focused, maximin-focused, etc., frameworks. For my purposes, it is only necessary to highlight that the kind of distributional problem best framed in terms of Weighing reasons is already recognized by a significant body of literature. That literature recognizes different facets that matter to distributive justice-including personal responsibility for opportunities, the significance of choices and abilities, the important role of a distributive agency, and the space for pursuing one's own ends or meaningful projects. Yet that literature (and the problems to which it responds) are not recognized as core discussions in human rights theory. One motivation for this might be the belief that human rights do not engage with Weighing reasons but rather with categorical requirements. I consider arguments for this below.

18 Rawls' maximin principle is described in his Theory of Justice (revised edition) (Rawls 1999: 72); some critiques of this view have questioned this permission as un-justified (Cohen 2008: $151 \mathrm{ff}$. .). 
For now, if human rights obligations include both Weighing reasons and Decisive reasons, then these must be parsed out when deliberating over the content of people's entitlements as a matter of right. To give content to obligations that engage Weighing reasons, some account of distributive fairness will be crucial. ${ }^{19}$ Bilchitz's (unsuccessful) attempt to provide such an account highlights that we need this kind of framework in settling the content of some human rights duties, such as those to fulfil.

So, returning to the example of the Greek government, taxing affluent people is perfectly justified to protect crucial health provisions for the most vulnerable in society. A variety of principles of distributive fairness might support this. A maximin principle would say that where the wealth of the affluent does not improve the condition of the worst off, and the simple existence of affluent people did not do that for health in Greece, contributions must be made by those who have greater advantages, but opportunities to pursue resources are nevertheless permitted only as long as pursuing them brings dividends to the least advantaged. There are no limits on what can be pursued that has this characteristic and taxation must not make the beneficial opportunities impossible. If, on the other hand, one were obliged to fulfil others' basic interests at whatever cost, globally, allowing people to pursue additional resources would be ruled out, as they can be expected to work to fulfil global basic interests regardless of any opportunity to obtain resources for their aims (Cf. Cohen 2008: n. 10). Treating human rights duties as unconditional requirements to fulfil basic interests misses this complexity.

If the above is right, then when resolving the duty content of rights and adjudicating specific cases, we need to be aware of the different kinds of reasons that it makes sense to take into account. Trying to apply Decisive reasoning where Weighing reasons are appropriate will create problems of resource and contribution sensitivity that Decisive reasons do not tell us how to solve. Treating human rights as generating categorical obligations also hides these differences leading to similar tangles. International standards recognize the need for resource sensitivity, as we shall soon see, but supply no principle for adjudicating these questions. When duty bearers appeal to lack of resources in fulfilling a right, a compelling response will need to appeal to a fair principle of distribution.

Weighing reasons are important for fulfilment duties because Decisive reasons give no positive account of how much of any important provision or benefit people must supply. To be pertinent in any context, we must be

19 Some theorists see human rights as a subset of justice, and distributive justice as on a par. They thus miss the possibility of these different types of duty and the different consequences of applying them (e.g., Tasioulas 2010: 654 ff. \& 659). 
faced with valuable aims, in the form of interests that matter for persons, as well as countervailing, though legitimate, considerations in the form of the aims and pursuits of those who would have to forego those pursuits to satisfy the valuable aims. Those two models of reasoning about considerations are pertinent to duties corresponding to both CivPol and EcoSoc rights. There is a difference between discriminatory or even neglectful considerations in deciding how police protections are to be distributed, and the question of how much police protection everyone should have, given the costs in a particular social context. The pertinence of both types of reasoning is as true of police protection budgets as of the decision over how many dialysis facilities a society should have.

\section{DECISIVE REASONS}

Whilst I have given some examples, I have not set out a general account of the kind of moral consideration that can constitute a Decisive reason in the sphere of human rights. These are reasons to disqualify a given range of considerations as relevant to how a person should be treated - thus also ruling out a Weighing reasons type deliberation on the basis of these considerations. That a person has important interests is not sufficient to establish reasoning as to the relevance or irrelevance of a consideration because that importance does not explain the kind of categorical decisiveness that can disqualify a consideration. The importance of an interest might, under certain circumstances, simply outweigh other interest considerations, depending on the numbers of interests in play. Thus, the need to improve road safety can outweigh road users' interests in efficient travel. However, to rule out or disqualify some considerations as relevant to how we ought to treat a person, we need reasons or values that are categorically superior so that other considerations do not count against them. That must be the case however many considerations of the disqualified kind could be stacked against this value. That an interest is important for a person's wellbeing, even hugely important, does not have this categorical character unless one has a special reason to promote it categorically. An example of such a consideration might be the inherent value in a person being respected in exercising her capacity to adopt goals and commitments, to develop these, prioritize amongst them, and to pursue them as personal life projects - projects that give direction to and shape her life. To value that capacity is to respect it, and to respect it means not seeking to usurp its exercise, impose conditions on it exercise, or undermine the possibility of its exercise. Failure to respect the sovereign exercise of this capacity in persons, for any reason other than upholding 
this very same respect, is wrongful because it treats their living distinct lives as subordinate to aims and priorities that are not their own.

Actions like enslavement and torture are in this way categorically wrongful; they disrespect a person as having sovereignty over the exercise of this capacity. The actions of slavery subordinate a person's capacity to adopt, prioritize, and pursue her ends to the priorities, and pursuits of the slave owner. Torture uses a person's sense of wellbeing (in her aversion to pain) to alter her priorities and commitments - e.g., the commitment not to disclose the location of her colleagues, thus subordinating her capacity to prioritize and pursue these commitments to the aims of the torturer. Imposing pain on someone may under certain circumstances be permissible, as in self-defense. There the permission to intervene is not a failure to respect self-sovereignty but rather an expression of it: upholding that it be respected for others. The value itself sets limits on its own exercise. Where the considerations for imposing pain on another or constraining her freedom fail to respect this self-sovereignty value, they are discounted as having no weight; and the actions they support are ruled out as (pro tanto) wrongful. With the race-based exclusion case, mentioned at the beginning of this paper, the literature contains a number of theories of discrimination and though some of those analyses overlap with this question they are not limited to it (Viz., Wasserstrom 1995; LippertRasmussen 2006; Gardner 2018). But the key question here is the narrower one of what kind of reason can not only outweigh, but also disqualify a race-based consideration for exclusion? Some accounts focus on the demeaning of the target, others on thwarting of a key interest (Hellman 2008; Moreau 2010). Some views focus on treating groups as less worthy of decent treatment (Shin 2009). However, to disqualify the consideration itself even as an interest that should be balanced with others in a weighing exercise, we simply reflect that it mistakenly uses the characteristic of race as grounds to dismiss the value in people exercising their capacity to form, develop, prioritize, and pursue commitments as the determinant of how they should be treated. The mistake disqualifies the consideration as having any weight against treating people in light of the capacity. Where countervailing considerations are not open to disqualification in this way, but have independent importance as people's interests, then the Weighing reasons model is appropriate.

\section{OBJECTIONS}

As I mentioned above, the Decisive reasons versus Weighing reasons distinction - and certainly the notion of principles of distributive societal 
justice-are not commonly appealed to as sources for the content of human rights standards. One reason for this may be a tendency to treat the analysis of duties and justified burdens associated with human rights as categorical obligations, meaning they unconditionally demand a certain outcome for each person and would thus rule out Weighing reasons as part of their analysis. I now respond to some arguments for this view.

\subsection{Weighing reasons as Decisive reasons}

The first objection is that we can and should re-describe human rights duties in categorical terms. In saying people have a right to a certain amount of health care we are saying that this is obligatory in some nonnegotiable sense. One way this could be done is by introducing obligations that are categorical but worded in a conditional way. ${ }^{20}$ In fact, the use of conditional wording is present in international legal documents associated specifically with fulfilling EcoSoc rights. ${ }^{21}$ The resources and infrastructure that should be present to fulfil these rights make the associated duties difficult to word unconditionally. Instead, resource sensitivity is introduced in the form of a duty to "progressively realize" them. In carrying out progressive realization, states are charged with taking all "appropriate steps" and employing "all available resources" towards the goal of fulfilling these rights. ${ }^{22}$ Thus, instead of a categorical obligation to supply certain outcomes, which would be resource insensitive, we have a duty to move towards those outcomes when certain conditions are met, which is thus sensitive to the resources that a state has available to it.

A categorical reading of the fulfilment duties associated with EcoSoc rights might imply an obligation to supply an outcome $\mathrm{O}$ that requires $\mathrm{R}$ resources. A duty to progressively realize $\mathrm{O}$ means that a state at any time $\mathrm{t}$ only has an obligation to realize $\mathrm{O}$ to the extent, $\mathrm{nO}$, that is possible with the resources, $\mathrm{nR}$, that the state has available to it at $\mathrm{t}$. There is a firm and categorical obligation here; yet it is not the obligation to fulfil the right, only to partially fulfil it to the extent, nO, possible at t. The duty to entirely fulfil the right, categorically, would only occur at a point $t^{\wedge}$, where $R$ resources were available to it. So, the duty is conditional on resource availability at any one time. If this analysis is correct, we should not have

20 Cf. Bilchitz's distinction between conditional and unconditional rights, (Bilchitz 2007: $78 \mathrm{ff}$.).

21 There is an important inconsistency in that EcoSoc rights are explicitly subject to such conditionally in the UN documents, such as General Comments 3, 10, 14 (CESCR 1990; $1998 ; 2000)$ where PolSci rights are not, or at least not systematically, yet protection and fulfilment duties associated with the latter clearly should be as I have stressed above.

22 For "appropriate steps" see (CESCR 2000: ss. 11 \& 49); for “available resources" see (CESCR 1990; 1998; 2000). 
to resort to Weighing reasons to resolve how to resource the provision of human rights fulfilment. We can instead re-describe those duties in categorical, albeit conditional, terms in terms.

The problem with this response is that the notion of "available resources" is being used as a descriptive term, when it could only be a normative concept. This is because what counts as "available" for a state to use depends on what it can legitimately extract from those who work for or within it. This will take the form of taxation, work contributions, or the configuring of property relations. Any physical or natural resource will need to be turned into exchangeable or useable resources; any already exchangeable or useable materials that are owned will need to change ownership. That means a state will need to make decisions about appropriate levels of taxation, ownership, wealth, property rights, and even labor in order to decide what resources are genuinely "available" to it. Of course, one could try restricting the notion of available resources to what a state has in its possession, or revenue, at any one time, to avoid these problems; but that would be an arbitrary choice given the point of using these resources. The plausible notion of an available resource will, then, depend on the burdens that a state can justifiably impose on people leading to benefits for others in terms of basic interest satisfaction. Consequently, it is clear that the level at which we set availability depends on what citizen contribution level is justified - a moral normative question. Some human rights literature takes a step in that direction by appealing to the concept of "reasonableness" in assessing what resources are "available" (Chenwi, 2013). But no account of reasonableness has been provided to address the essential question of how to weigh conflicting interests in assigning burdens. This is the Weighing reasons question: at any one time, $t$, what counts as a duty will depend on available resources, which in turn depends on the Weighing reasons that apply to the fair social distribution of benefits and burdens.

A component of the progressive realization doctrine that might be used to try to prescribe categorical requirements for states is the idea that EcoSoc rights include "core obligations" associated (CESCR 200: ss. $43 \mathrm{ff}$.). As I have said, my concern here is not with duties associated only with EcoSoc rights but with obligations cutting across those kinds of distinctions. So, the claim some EcoSoc obligations might be categorical does not threaten my analysis of two types of reasons at the heart of human rights obligations. However, if the claim is that a scheme for fulfilment provisions in which there are certain mandated outcomes is a categorical requirement, this does conflict with the view of duties and justified burdens I have proposed. The international doctrine associated with core obligations, 
however, either highlights rights that are easily accounted for as Decisive reasons - based on the distinction I have proposed - e.g., that EcoSoc services should not be provided in a discriminatory way, or would need to be somewhat sensitive to resource availability (Bilchitz 2007: $220 \mathrm{ff}$.).

\section{2. "Rights" versus Weighing reasons?}

Some theorists associate human rights with a technical notion of "rights" that conceptually implies an entitlement to a specific content - whether it is an outcome or form of treatment - that must be known in advance. The Weighing reasons analysis does not give us any definite content for the entitlement, only for the principle that will be employed to determine it in any specific case. So it seems to undermine human rights as rights (see Bilchitz's worry, ibid). In itself, this is not a strong point. For there is no reason to think that human rights have to be rights in that very technical sense, as opposed to important obligations states have towards their citizens. $^{23}$

A feature more centrally associated with human rights, however, is their universality. Some authors interpret this as human rights encompassing justified claims that can be claimed by all persons and claimed equally, regardless of circumstances or social membership (O'Neill 1996: $130 \mathrm{ff}$.). Onora O'Neill uses this premise to argue that rights to goods and services cannot be human rights: to be able to claim them justifiably, and - for the purposes of this paper - fairly, one must claim them from a certain infrastructure with specific types of responsible agents (O'Neill 1996: 130136). Importantly, a state must have fairly allocated the duties to supply the content of the rights. However, what exactly a person is entitled to have as a matter of fulfilment of their rights, depends on what it is in any given context fair to impose as a burden on others. Given that this may differ with context, the claim cannot be justifiably and equally made by all persons, regardless of circumstances or social membership. That, in turn, implies the right is not universal, so that on this view it is not a human right.

Yet, this objection does not deny that protection or fulfilment claims can ever be justifiably made. It simply says they are not universal in the right sense. Institutional orders can be set up such that justifiable, fair, claims can be made. So, why is universality, in this particular sense of universality, essential to defining human rights? Universality of this formal kind is just one dimension that might pick out what is special or distinctive in human rights; a different trait might be their importance or

23 James Griffin, for example, rejects the need to use the technical sense of a right to analyze human rights (Griffin 2014: 210). 
urgency, or even their ability to place limits on the legitimacy of political institutions. There is no obvious reason why all human rights should apply independently of institutional context - in fact, that very condition is challenged by "political theories" of human rights (e.g., Beitz's theory, Beitz 2008). Whatever the right answer as to the defining feature/s of human rights standards, the claim is not that standards based on Weighing reasons, and thus lacking the requisite universality, fail to be normative standards at all. If it is admitted that such standards exist and under the right conditions they can justify normative claims, then whether we call these human rights or not seems more a matter of nomenclature than significant substance.

\subsection{Does this weaken EcoSoc human rights?}

A final objection I will consider is that this approach, with its two models of reasoning underpinning different types of obligations, weakens EcoSoc human rights claims. EcoSoc rights rely more heavily on fulfilment as their core mission. Which is to say that whilst there are cases where taking EcoSoc opportunities away-e.g., by intentionally or negligently destroying a source of water - is a violation and one consistent with a Decisive reasons approach, the key question for EcoSoc rights is how to fulfil certain EcoSoc conditions for people. By introducing Weighing reasons, and with them the idea that an infrastructure of distribution that is capable of fairness is needed for these rights to apply, I would seem to have made EcoSoc rights less easily claimable and less practically useful outside certain specific societal contexts.

Whilst this may be true, it is important to point out that any alternative formulation of the duties and justified burdens associated with human rights will suffer similar or equivalent problems. Re-describing the duty to fulfil as a categorical requirement still faces the problem of how these requirements are to be supplied and by whom. One could indeed abandon the idea that there are countervailing considerations such that we must engage in Weighing. But that means giving up an essential component of reasonableness and fairness in practical and political reason. It would be a victory by stipulation only, not one responding to the practical problem of the existence of legitimate conflicting considerations. If we accept the need to adjudicate between these different considerations, then Weighing reasons do not weaken human rights duties but provide the only kind of solution that will give a significant portion of them some rational content. 


\section{CONCLUSION}

In conclusion, I have identified two types of reasons - or two models of reasoning - when determining the content of certain human rights obligations and justified burdens. The Decisive reasons model offers us a way of understanding categorical duties, whereas the Weighing reasons model is engaged when we must consider interests and considerations that need to be balanced. Provisions and interpretations that are compatible with both models are present in international human rights documents, although these documents do not explicitly recognize the need for either model, or any model altogether. I have argued that these models are, however, both necessary to make sense of, and give content to, different types of human rights responsibilities. I stress, these two types of reasoning are not designed to undermine any one type of right or duty - instead, they cut across different traditional distinctions between types of rights (Economic and Social versus Civil and Political); and they are both ways of explaining the duties as genuine obligations. Yet, without sensitivity to these forms of reasoning, trying to give content to our human rights obligations will lead to troubling confusions. Not all human rights duties are categorical and we need an account of how to determine those duties when they are not.

\section{BIBLIOGRAPHY}

Bedau, H. A., 1979: 'Human Rights and Foreign Assistance Programs', in P. G. Brown and D. Maclean, eds., Human Rights and US Foreign Policy, Lexington Mass.: Lexignton Books

Bilchitz, D., 2007: Poverty and Fundamental Rights, Oxford: Oxford University Press

Buchanan, A., 2004: Justice, Legitimacy, and Self-Determination, Oxford: Oxford University Press

Brock, G., 2009: Global Justice: A Cosmopolitan Account, Oxford: Oxford University Press

Casal, P., 2007: 'Why sufficiency is not enough', Ethics 117(2): 296-326

Charles, B., 2008: The Idea of Human Rights. Oxford: Oxford University Press

Chenwi, L., 2013: 'Unpacking "progressive realisation”, its relation to resources, minimum core and reasonableness, and some methodological considerations for assessing compliance', De Jure, 46(3): 742-769

Christiansen, E. C., 2007: 'Adjudicating non-justiciable rights: socio-economic rights and the South African Constitutional Court', 38(2): 321-386

Cohen, G. A., 2008: Rescuing justice and equality, Camb. Mass.: Harvard University Press

Committee on Economic, Social, and Cultural Rights (CESCR), 1990: General Comment 3, United Nations 
Committee on Economic, Social, and Cultural Rights (CESCR), 1998: General Comment 10, United Nations

Committee on Economic, Social, and Cultural Rights (CESCR), 1999a: General Comment 12, United Nations

Committee on Economic, Social, and Cultural Rights (CESCR), 1999b: General Comment 13, United Nations

Committee on Economic, Social, and Cultural Rights (CESCR), 2000: General Comment 14, United Nations

Committee on Economic, Social and Cultural Rights (CESCR), 2015, 27 October: Concluding Observations, UN Doc. E/C.12/GRC/CO/2, United Nations, e.g., paras $19 \& 20$

Cranston, M., 1973: What Are Human Rights, Taplinger Publishing, New York

Crisp, R., 2003: 'Equality, priority, and compassion', Ethics 113(4): 745-763

Dworkin, R., 1984: 'Rights as trumps', in Waldron, J., ed., 1984, Theories of Rights, Oxford: Oxford University Press

-2000: Sovereign virtue and the practice of equality, Cam. Mass: Harvard University Press

— 2010: Justice for Hedgehogs, Cambridge, MA: Belknap Press

Frankfurt, H., 1987: 'Equality as a moral ideal', Ethics 98(1): 21-43

Gardner, J., 2018: 'Discrimination, the good, the bad, and the wrongful', Proceedings of the Aristotelian Society, CXVIII(1)

Gilabert, P., 2012: From global poverty to global equality, Oxford: Oxford University Press

Griffin, J., 2014 : 'Replies', in Crisp, R., ed., 2014, Griffin on human rights, Oxford: Oxford University Press

Hellman, Deborah, 2008: Why is Discrimination Wrong?, Cambridge, MA: Harvard University Press

Kamm, F., 2007: Intricate Ethics, Oxford University Press

Lippert-Rasmussen, K., 2006: 'The Badness of Discrimination', Ethical Theory and Moral Practice, 9: 167-185

McDowell, J., 1998, originally published 1978: 'Are moral requirements hypothetical imperatives?', Mind, value, and reality, Cambridge Mass.: Harvard University Press

Meckled-Garcia, S., 2016: 'Two concepts of justice, and of its scope', Critical Review of International Social and Political Philosophy, 19: 534-554

Miller, R., 2010: Globalizing justice, Oxford: Oxford University Press,

Möller, K., 2009: 'Two concepts of positive liberty: against reason blocking', Oxford Journal of Legal Studies, 29(4): 757-786

Moreau, S., 2010: 'What is Discrimination?' Philosophy and Public Affairs 38: 143179

O'Neill, O., 1996: Towards Justice and Virtue, NewYork: Cambridge University Press

Rawls, J., 1999: A Theory of Justice (revised edition), Cambridge Mass.: Belknap Press

Rawls, J., 2001: Justice as fairness, a restatement, Cam. Mass.: Belknap Press

Sachs, A., 2000: 'Social and Economic Rights, can they be made justiciable?', S. M. U. Law Rev., 53: 1381-1391

Scanlon, T. M., 1998: What we owe each other, Cambridge Mass.: Belknap Press 
- 2004: 'Reasons: A Puzzling Duality?', In Wallace, R. J., Pettit, P., Scheffler, S., \& Smith, M., eds., 2004: Reason and Value: Themes From the Moral Philosophy of Joseph Raz, Oxford: Clarendon Press

Sher, G., 1997: Beyond Neutrality. Cambridge University Press

Shin, Patrick, 2009: 'The Substantive Principle of Equal Treatment', Legal Theory, 15: $149-172$

Shue, H., 1996 ( $2^{\text {nd }}$ Ed.): Basic Rights: Subsistence, Affluence, and US Foreign Policy, Princeton: Princeton University Press

Stemplowska, S., 2009: 'On the real worlds duties imposed on us by human rights', J. Social Philosophy, 40(4): 466-487

Tasioulas, J., 2010: 'Taking rights out of human rights, Ethics, 120(4): 647-678

- 2015: 'On the foundations of human rights', in Cruft, R., Liao, S. M., Renzo, M., eds., Philosophical foundations of human rights, Oxford: Oxford University Press

Waldron, J., 2000: 'Pildes on Dworkin's theory of rights', The Journal of Legal Studies, 29(1): 301-307

— 1989: 'Conflicts of rights', Ethics, 99(3): 503-519

Wasserstrom, R., 1995: 'Preferential Treatment, Color-Blindness, and the Evils of Racism', in Steven Cahn, ed. The Affirmative Action Debate, New York: Routledge, pp. 153-168

United Nations, 1966/76: International Convenant on Civil and Political Rights (ICCPR)

United Nations, 1966/76: International Covenant on Economic, Social, and Cultural Rights (ICESCR) 